\title{
Identification of Two Parasitic Nematodes in The Rhizosphere of Centranthera grandiflora in Pingbian, Yunnan
}

\author{
Fu yan ${ }^{1}$, Chen yuewen ${ }^{1}$, Li wei $^{2}$, Yang $\mathrm{Wei}^{3}$, Zhou Yinli $^{1, \mathrm{a}}$ \\ ${ }^{1}$ Laboratory of Biological Resources Research and Utilization in Southern Yunnan, Honghe University, Mengzi 661100 \\ ${ }^{2}$ Bureau of Agriculture, Rural areas Science and Technology, Pingbian county, Yunnan, Pingbian 661299 \\ ${ }^{3}$ Commercial college, Honghe University, Mengzi 661100
}

\begin{abstract}
Centranthera grandiflora, a kind of traditional Chinese medicinal materials in Yunnan Province, has very high medicinal value. However, constant expansion of the plantation has resulted in worsening root diseases, an obstacle of continuous cropping. From 2018 to 2019, the author investigated the parasitic nematodes in the rhizosphere of Centranthera grandiflora in Pingbian County, Yunnan province, and identified them according to their morphological characteristics. The results showed that there were two kinds of parasitic nematodes harmful to Centranthera grandiflora root in Pingbian County, Yunnan: Tylenchorhynchus capitatus Allen, 1955 and Helicotylenchus dihystera (Cobb,1893) sher, 1961.
\end{abstract}

\section{Introduction}

Centranthera grandiflora, also known as smooth wild bean, Small health potion, etc., is the whole grass of Centranthera grandiflora under the Scrophulariaceae category ${ }^{[1]}$. People call it " Plants gold in the mountains", and it is mainly grown in Guangxi, Guizhou, Yunnan and other places ${ }^{[2]}$. Centranthera grandiflora has antimyocardial ischemia and anticoagulant effect ${ }^{[3]}$. It has significant effects of promoting blood circulation and removing blood stasis, providing energy and enriching blood, as well as curative effects of external bleeding, internal bleeding and gastroenteritis (Yunnan Honghe Chinese Herbal Medicine Manual). Centranthera grandiflora in Yunnan is of excellent quality, making it popular in both domestic and international markets. It is currently grown in Wenshan, Honghe and other areas. It's a rare Chinese medicine in the local area with a huge demand. Due to the expansion of plantation, more diseases and pests are emerging, which seriously affected the quality of Centranthera grandiflora, especially nematode affecting the root. Plant parasitic nematodes can transmit viruses, fungi and bacteria to form complex diseases [4]. Tylenchorhynchus and Helicotylenchus are important plant pathogen nematodes, which can harm plant roots and cause poor growth of the aboveground. Parasitic nematodes have become one of the important factors impeding the growth of Centranthera grandiflora. So far, there are few studies on parasitic nematodes of Centranthera grandiflora. Therefore, the author investigated and identified the species of parasitic nematodes affecting Centranthera grandiflora in Pingbian county, Yunnan province during 2018 and 2019, in order to provide references for the diagnosis and control of root diseases of Centranthera grandiflora.

\section{Materials and Methods}

\subsection{Collection of rhizosphere soil of Centranthera grandiflora}

The 10 samples of rhizosphere soil collected from the planting area of Centranthera grandiflora in Pingbian County in 2019 were studied based on key symptoms including weak growth of aboveground, poor growth, wilting, browning or swollen and deformed roots. Rhizosphere soil samples were collected by "quartering" method and put into the marked self-sealing bag, which was brought back to the lab and separated nematodes timely.

\subsection{Collection of rhizosphere soil of Centranthera grandiflora}

Author names should be typed in 9-point Arial. The style for the names is First Names then Last Name, with a comma after all but the last two names, which are separated by "and". Do not use academic titles.

Affiliations of authors should be typed in italic 8point Arial. They should be preceded by a numerical superscript corresponding to the same superscript after the name of the author concerned. Please ensure that affiliations are as full and complete as possible and include the country. 


\section{Results and Analysis}

Two species of parasitic nematodes were isolated and identified from soil samples collected from the planting area of Centranthera grandiflora in Pingbian, Yunnan. The first species was Tylenchorhynchus capitatus Allen, 1955 that is classified as Tylenchorhynchus in the subfamily of Tylenchorhynchidae under Tylenchida. The second species was Helicotylenchus dihystera (Cobb,1893) sher, 1961, classified as Helicotylenchus in the Hoplolaiminae family under Hoplolaimida.

\subsection{Tylenchorhynchus capitatus}

Morphological features: the body is ventrally curved after the fixation, which is 582-657 $\mu \mathrm{m}$ long and 20-23 $\mu \mathrm{m}$ wide with fine lines. The excretion hole is usually located in the front half of the esophagus gland. The meniscus is not obvious, the lip area round, protruding, and the base being over-contracted. It has a strong stylet, the base of which is round. The middle esophagus bulb is ovoid, the isthmus is narrow, the esophagus gland is long and pear-shaped, which does not cover the intestine, has a clear boundary with intestine, and the cardia is obvious. The vulva is usually concave in the middle of the body, and the two ovaries feature straight extension with single or multiple lines of oocytes. The conical tail is ventral curved and tapering, with the tail being 38.9$47.0 \mu \mathrm{m}$ in length. The tail has fine, regular or irregular ring pattern. The heart-shaped tail end has no ring pattern, and protrudes in the body ring. The morphological characteristics are shown in Figure 1, and the comparison of measured values and literature records are shown in Table 1.

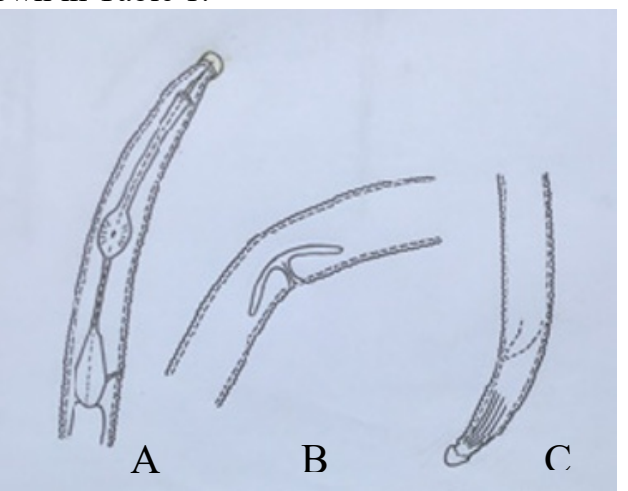

Figure 1. Tylenchorhynchus capitatus

A. Female anterior; B. Female vulva; C. Female tail

\subsection{Helicotylenchus dihystera}

Morphological features: After killed in the water bath, the female body was spirally shaped, with clear ring lines, posterior esophageal gland covering the intestine with a long ventral cover. Some female body only circled around the rear half of the body for 1 circle, while some of the front part was almost straight, and the rear part almost rotated for 3 circles. The head is semispherical, or slightly flat in the front end. It has 4-5 invisible rings, and the front of the base ball of the stylet feature flat to dentate shape. The excretory hole is located before the bowel valve of esophagus, the labial of vulva is slightly sunken with two gonads facing each other. Oocytes are arranged in a single row, with round oocyst that has no sperm inside. The conical tail is ventral curved and asymmetric cone, the ventral end of the tail has a prominent protuberance.

The morphological characteristics are shown in Figure 2, and the comparison of measured values of Helicotylenchus dihystera and those in the literature are shown in Table 2.

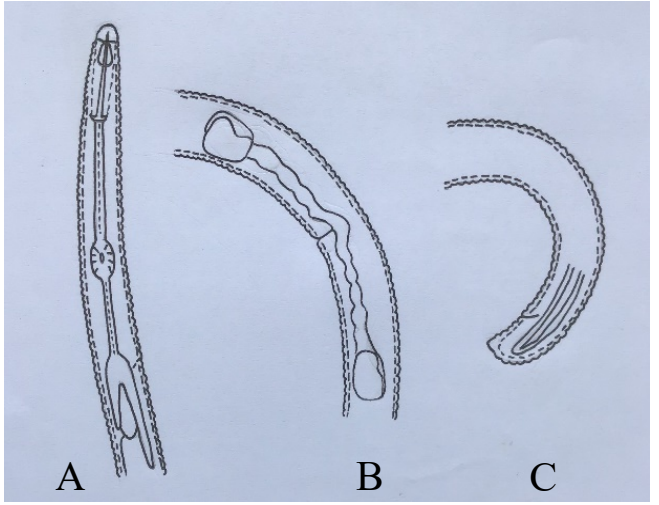

Figure2. Helicotylenchus dihystera

A. Female anterior; B. Female vulva; C. Female tail

\section{Discussion}

The results showed that there were two parasitic nematodes in the rhizosphere of Centranthera grandiflora in Pinbian county Yunnan province: one was Tylenchorhynchus capitatus Allen, 1955; the other was the Helicotylenchus dihystera (Cobb,1893) sher, 1961. The morphology characteristics of Tylenchorhynchus capitatus is basically consistent with descriptions by Feng Zhixin ${ }^{[7]}$. In the morphological index measurments, a (length/width) is slightly smaller than the literature value, and the stylet is slightly longer than the literature value, while the rest of the indicators are consistent with the literature records. This is probably due to geographical differences between populations. Therefore, it was identified as Tylenchorhynchus capitatus. The morphological characteristics of the Helicotylenchus dihystera were consistent with descriptions by Feng Zhixin in 1982, and the morphological indicators were basically consistent with the values in the literature ${ }^{[7]}$, so it was identified as the Helicotylenchus dihystera. The damages of these two nematodes to Centranthera grandiflora need further study.

\section{Acknowledgments}

This work was financially supported by National innovation and entrepreneurship training program for college students in China(201910687010) ; Doctor Special Research fund of Honghe University(XJ17B10); Cooperative cultivation plan for excellent agricultural and forestry talents of plant protection 
specialty;Innovation training program for college students in yunnan province 2019.

Table 1 The Measured Values of Tylenchorhynchus capitatus of Centranthera grandiflora and those reported in the literature

\begin{tabular}{ccc}
\hline Morphological index & Group of Mengzi & Literature $^{[7]}$ \\
\hline $\mathrm{n}$ & 12 c & 10 q \\
$\mathrm{L}(\mu \mathrm{m})$ & $617.0 \pm 53.0(581.7 \sim 657.0)$ & $(580 \sim 630)$ \\
$\mathrm{W}(\mu \mathrm{m})$ & $21.5 \pm 0.4(20.4 \sim 22.7)$ & $(21 \sim 27)$ \\
Tail $(\mu \mathrm{m})$ & $42.5 \pm 5.4(38.9 \sim 47.0)$ & $(37 \sim 53)$ \\
$\mathrm{a}$ & $27.8 \pm 0.4(25.4 \sim 29.9)$ & $(30 \sim 38)$ \\
$\mathrm{b}$ & $5.0 \pm 0.1(4.9 \sim 5.1)$ & $(5.0 \sim 5.8)$ \\
$\mathrm{c}$ & $14.5 \pm 0.4(14.0 \sim 15.1)$ & $(12 \sim 17)$ \\
A-vulva & $338.2 \pm 55.8(299.0 \sim 376.0)$ & $(51 \sim 58)$ \\
V & $54.7 \pm 4.1(51.3 \sim 57.9)$ & $(2.0 \sim 4.0)$ \\
ST & $17.2 \pm 0.9(16.8 \sim 17.9)$ & $(108 \sim 137)$ \\
DGO & $3.7 \pm 0.9(2.1 \sim 4.6)$ & $(138 \sim 158)$ \\
Ex.p & $132.0 \pm 13.9(122.7 \sim 143.8)$ & $(15 \sim 20)$ \\
Oes & $145.8 \pm 11.9(138.4 \sim 155.1)$ & $(10 \sim 12)$ \\
Bulbl & $19.1 \pm 2.0(16.4 \sim 21.2)$ & \\
bulbw & $11.7 \pm 1.3(10.7 \sim 12.8)$ & \\
\hline
\end{tabular}

Table 2 The Measured Values of Helicotylenchus dihystera of Centranthera Grandiflora and those reported in the literature

\begin{tabular}{ccc}
\hline Morphological index & Group of Mengzi & iterature $^{[7]}$ \\
\hline $\mathrm{n}$ & 13 q & $10+q$ \\
$\mathrm{~L}(\mu \mathrm{m})$ & $709.8 \pm 78.7(624.8 \sim 930.0)$ & $(620 \sim 840)$ \\
$\mathrm{W}(\mu \mathrm{m})$ & $25.2 \pm 3.2(21.3 \sim 32.9)$ & $(20.5 \sim 27.5)$ \\
$\mathrm{AW}(\mu \mathrm{m})$ & $16.2 \pm 2.5(12.0 \sim 21.3)$ & $(10.5 \sim 24.5)$ \\
$\mathrm{Tail}(\mu \mathrm{m})$ & $17.6 \pm 2.6(14.4 \sim 24.63)$ & $(21 \sim 32)$ \\
$\mathrm{a}$ & $28.3 \pm 1.2(26.0 \sim 30.2)$ & $(4.4 \sim 6.1)$ \\
$\mathrm{b}$ & $5.0 \pm 0.2(4.6 \sim 5.3)$ & $(35 \sim 49)$ \\
$\mathrm{c}$ & $40.7 \pm 2.9(35.4 \sim 43.9)$ & $(0.8 \sim 1.2)$ \\
$\mathrm{c}^{\prime}$ & $1.1 \pm 0.1(1 \sim 1.2)$ & $(24 \sim 29)$ \\
$\mathrm{ST}$ & $25.1 \pm 1.6(23.7 \sim 26.4)$ & \\
$\mathrm{A}-\mathrm{vulva}$ & $454.0 \pm 49.7(398.8 \sim 593.1)$ & $(60.6 \sim 65.9)$ \\
$\mathrm{V}$ & $64.0 \pm 1.5(60.0 \sim 66.2)$ & $(8 \sim 11.2)$ \\
$\mathrm{DGO}$ & $10.2 \pm 1.1(8.3 \sim 11.8)$ &
\end{tabular}

\section{References}

1. Liang Juzhong,Zhang Jiasuo,Ma Xiaoben,et al. Identification of the chemical component in Centranthera grandiflora. Bulletin of Chinese Materia Medica, 5:37-38(1985)

2. $\mathrm{Hu}$ qiong. Study on chemical constituents of Centranthera grandiflora . Clinical Journal of Chinese Medicine, 8,22:49-53(2016)

3. Liao Liping,Zhang Zijia,Hu Zibi, et al. Iridoid glycosides from Centranthera grandiflora. Chinese Traditional and Herbal Drugs, 43,12:23692371(2012)

4. $\mathrm{Yu}$ Shengfu,Hu Xianqi,Wang Yang. Plant disease complexes involving pathogenic nemat odes . Acta Phytopathologica Sinica.29,1:1-7(1999).

5. Fen Zhixing. Plant nematology[M]. China Agriculture Press ,Bei jing,170 -172(2000)
6. LiuWeizhi.Taxonomy of plant nematodes[M]. China Agriculture Press ,Bei jing,106-110(2006)

7. Liu Weizhi. Nematode Flora of Plants[M]. China Agriculture Press ,Bei jing,372-389(2003). 